\title{
Transient epileptic amnesia differentiated from psychogenic "fugue": neuropsychological, EEG, and PET findings
}

\author{
M D Kopelman, C P Panayiotopoulos, P Lewis
}

\begin{abstract}
A patient had repeated episodes of transient loss of memory, which had been attributed to psychogenic causes. Preservation of his sense of personal identity and the presence of repetitive questioning indicated an organic basis, however, and the multiplicity of the attacks and their brief duration suggested an epileptic aetiology. Although three standard EEGs, CT and MRI were all normal, two sleep EEGs confirmed bilateral foci in the temporal lobes. The attacks responded to an anticonvulsant. A fluoro-deoxyglucose PET scan, performed a few months after the most recent attack, was normal. The patient also had impaired anterograde memory that persisted six months after recovery from the acute attacks.
\end{abstract}

(F Neurol Neurosurg Psychiatry 1994;57:1002-1004)

In the past two decades, several papers have drawn attention to epilepsy as a possible cause of transient global amnesia in a few patients. ${ }^{1-4}$ For example, Hodges and colleagues $^{5-7}$ found that $7 \%$ of 114 patients with transient global amnesia had an epileptic aetiology, despite known cases of epilepsy having been carefully excluded from the study. These authors found that those cases who had multiple and/or brief attacks (less than an hour) were most likely to manifest later epilepsy, (compare ${ }^{34}$ ) although routine EEGs and CT had been unremarkable in all their epileptic cases. ${ }^{7}$ Kapur and colleagues ${ }^{8}$ described neuropsychological findings in one such patient in whom they found a persistent interictal retrograde amnesia with only a minor degree of interictal anterograde memory impairment; and they argued that similar assessments should be conducted in other patients.

The present study reports a case of what Kapur $^{4}$ termed "transient epileptic amnesia" (transient global amnesia secondary to seizure activity in the temporal lobes) including neuropsychological, EEG, and PET findings. It illustrates the great importance of differentiating transient organic amnesia from psychogenic amnesia, such as "fugue states".

\section{Case report}

The patient was first seen in September 1991, when aged 54 . He arrived saying "I'm having fugues, Doc" having been given a diagnosis of psychogenic amnesia elsewhere. After a "collapse" in February 1990, for which a good description was not available, his wife witnessed a second attack in May 1990. Shortly before they were going to bed, he bent down to pick up a cup of coffee, and started to clench and unclench his hands transiently. He did not seem to understand what his wife said, and he moved into the kitchen where he looked around the room and "through" his wife for one or two minutes, seeming perplexed and confused, and then asked repetitive questions: "What day is it? ... What have I been doing? ... Why am I not at work? ... Where do I work?" His wife asked if he knew who or where he was, and he did. He "came round" one hour later, after which he went to bed and was fine in the morning. The next month, there was a further attack when he was at the helm of a boat, sailing round the Isle of Man: suddenly, he demanded of his fellow yachtsman where they were, and he seemed very agitated, asking repetitive questions, until he came round an hour later. On this occasion, and during two further attacks at home lasting half an hour, there was no hand clenching nor any other evidence suggestive of epilepsy. As well as these symptoms, the patient complained of "gaps" in his memory, such as for a period when his wife was in hospital for a breast abscess in 1987; and he also mentioned forgetfulness for appointments, everyday tasks, what he had read in the newspaper, and even for the location of familiar shops. On the other hand, it was noticeable that he remembered previous medical consultations with pernickety detail, and he never failed to attend medical appointments.

There was a family history of possible epilepsy in a niece and of dementia in the patient's mother. A Cambridge graduate, he had worked as a partner in a small business for 20 years, but had lost his job in 1989 because of personality differences (not because of any memory problems). He had been seen previously by a neurologist and a psychiatrist in his local hospital where, after 
Table 1 General cognitive tests

\begin{tabular}{lll}
\hline & September 1991 & September 1992 \\
\hline WAIS-R: & & \\
Verbal IQ & 138 & 131 \\
Performance IQ & 114 & 117 \\
Full scale IQ & 131 & 129 \\
Frontal tests: & 43 (intact) & 42 (intact) \\
FAS verbal fluency & 4 (intact) & 1 (intact) \\
Cognitive estimates & & 6 (intact) \\
Card sorting & - & 0 \\
$\quad$ Categories & - & \\
\hline
\end{tabular}

Table 2 Memory tests

\begin{tabular}{lll}
\hline & September 1991 & September 1992 \\
\hline & Anterograde tests \\
Logical memory: & $9 \cdot 5 / 23$ & $8 \cdot 5 / 23$ \\
Immediate & $8 \cdot 0 / 23$ & $8 \cdot 5 / 23$ \\
45 minutes & $48 / 70$ & $48 / 70$ \\
Object learning & & \\
Recognition memory: & $45 / 50$ & $44 / 50$ \\
Words & $42 / 50$ & $38 / 50$ \\
Faces & $98 \cdot 0$ & $96 \cdot 75$ \\
"AMQ" & & 106 \\
WMS-R general MQ & & \\
& Retrograde tests & \\
News events test & & $79 \%$ (intact) \\
Recall & & $96 \%$ (intact) \\
Recognition & & \\
Autobiographical interview (AMI) & \\
Facts: & & $21 / 21$ (intact) \\
Childhood & & $18 / 21$ (intact) \\
Young adult & & $18 / 21$ (borderline) \\
Recent & & $5 \cdot 0 / 9$ (borderline) \\
Incidents: & $6 \cdot 0 / 9$ (borderline) \\
Childhood & & $7 \cdot 5 / 9$ (intact) \\
Young adult & &
\end{tabular}

two routine EEGs, two CT scans, and cognitive testing, a tentative diagnosis of psychogenic amnesia had been made, and he had been treated with an antidepressant and a benzodiazepine.

\section{Clinical assessment, investigations, and progress}

An initial diagnosis of transient global amnesia was made based on the clinical history. Various investigations including EEG studies were organised, and a brief admission arranged which, for administrative reasons, did not take place for four months, during which the patient had a further four attacks, identical to the previous ones. In the last of these attacks (although not in the others) clenching of the right hand was noted by his wife.

Various psychological tests were carried out at the initial assessment (tables 1 and 2). His verbal and full scale $\mathrm{IQ}^{9}$ were consistent with his educational accomplishments, although there did seem to be a relative decrement in performance IQ. Scores on the frontal lobe tests ${ }^{10}$ did not indicate any abnormality. The scores on the anterograde memory tests, ${ }^{11-13}$ however, were not as high as expected. After using published norms ${ }^{14}$ to convert these scores into "memory quotient" equivalents (with a population mean of 100 and SD of 15), an overall anterograde memory quotient (AMQ) of 98.0 was obtained, consistent with the population mean but 33 points below the patient's full scale IQ.
A standard blood screen was normal, as were a chest radiograph, ECG, and MRI and a fluoro-deoxyglucose PET (performed six months after cessation of the attacks).

A standard EEG was normal, but two sleep EEGs showed frequent midtemporal sharp and slow wave complexes, arising independently in the right and left hemispheres. After a trial of carbamazepine, which produced adverse effects, he was started on phenytoin in February 1992, rising to a dose of $300 \mathrm{mg}$ daily. No further attacks were recorded in the next 15 months, and there has been only one equivocal attack in the 21 months since this drug was commenced.

Further neuropsychological testing was conducted after six months of treatment. Results presented in tables 1 and 2 show that performance on the IQ, frontal, and anterograde memory tests was virtually identical to the (pretreatment) scores obtained a year earlier, although the verbal-performance IQ discrepancy had narrowed to 14 points. The $A M Q$ was unchanged; and the General MQ from the WMS-R scale ${ }^{15}$ gave a decrement of 23 points, relative to full scale IQ. On a retrograde memory test, requiring recall and recognition of pictures of famous news events, ${ }^{14}$ the patient performed at a superior level; and his memory for facts about his past on a semistructured interview (AMI) ${ }^{16}$ was also intact. He was hesitant, however, in recalling incidents from his childhood or early adult life, and his scores were at a "borderline" level according to published norms. ${ }^{16}$

\section{Discussion}

The patient had previously been given a diagnosis of psychogenic amnesia, and he believed himself to be experiencing "fugue states". His wife had very astutely established, however, that there was no loss of the sense of personal identity during his attacks, and he had displayed the recurrent repetitive questioning that is characteristic of transient global amnesia. Loss of personal identity is a cardinal feature of psychogenic "fugues", ${ }^{17} 18$ but seldom arises in organic amnesia except in advanced dementia; whereas repetitive questioning is prominent in transient organic amnesic states, but not in psychogenic fugue. ${ }^{517}$ Although it is true that his episodes had been preceded by a stressful life event (his dismissal from his job), attacks of transient global amnesia are preceded by stressful antecedent events in $14 \%$ to $33 \%$ of cases. ${ }^{35}$

Apart from brief hand clenching in two of the attacks, the patient did not show the automatisms or the degree of impaired consciousness (his wife could converse with him) that characterise "pure amnestic seizures" 19 and complex partial status epilepticus. The clue to the epileptic basis of the disorder lay in the frequency of the attacks and their relative brevity, both points previously noted by others. ${ }^{347} \mathrm{He}$ had probably had nine attacks, lasting between 30 minutes and one hour each. His routine EEGs and CT, and a subsequent PET, were all normal, ${ }^{7}$ but two sleep 
EEGs showed bitemporal spike and sharp wave foci. The attacks responded to phenytoin.

On cognitive assessment, he showed fairly severe impairment at anterograde memory tests, relative to his verbal and full scale IQ, which has persisted virtually unchanged after anticonvulsant treatment. Although he complained of "gaps" in his memory, his recollection of news events and of facts from his own life were intact on formal testing, but he was somewhat hesitant in retrieving incidents from his childhood and early adult life. A deficit in anterograde memory with little or no impairment on retrograde tests is what would be expected from bilateral dysfunction in the medial temporal lobes, ${ }^{20-22}$ but this pattern contrasts with the retrograde amnesia reported by our patient's Kapur et $a l^{8}$ presumably because of somewhat different locations of the epileptic foci. Although our patient's attacks had commenced late in life, neither MRI nor PET showed any evidence of infarction or ischaemia; nor did the clinical or neuropsychological features suggest a global dementing disorder. His persisting impairment in anterograde memory must result either from microscopic infarcts, not evident on his MRI scan, or from residual activity at the temporal lobe foci.

We are grateful to Hana Laing, Nicola Stanhope, and Robin Green for contributing to the psychological testing and to Claire Hook for typing various drafts of this manuscript.

1 Heathfield KWG, Croft PB, Swash M. The syndrome of transient global amnesia. Brain 1973;96:729-36.

Fisher CM. Transient global amnesia. Arch Neurol 1982, 39:605-8

3 Miller JW, Petersen RC, Metter EJ, Millikan $\mathrm{CH}$,
Yanagihara T. Transient global amnesia: clinical characteristics and prognosis. Neurology 1987;37:733-7.

4 Kapur N. Transient epiletic amnesia: a clinically distinct form of neurological memory disorder. In: Markowitsch HJ, ed. Transient global amnesia and related disorders. Lewiston, NY: Hogrefe and Huber, 1990.

5 Hodges JR, Ward CD. Observations during transient global amnesia: a behavioural and neuropsychological global amnesia: a behavioural and neurop

6 Hodges J, Oxbury SM. Persistent memory impairment following transient global amnesia. $\mathcal{F}$ Clin Exp Neurol 1990;12:904-20.

7 Hodges J, Warlow CP. The aetiology of transient global amnesia. Brain 1990;113:639-57.

8 Kapur N, Young A, Bateman D, Kennedy P. Focal retrograde amnesia: a long term clinical and neuropsychological follow-up. Cortex 1989;25:387-402.

9 Wechsler D. Wechsler Adult Intelligence Scale-Revised. London: Psychological Corporation, 1981.

10 Shallice T. Specific impairments of planning. Philos Trans $R$ Soc Lond Biol 1982;298:199-209.

11 Wechsler D. A standard memory scale for clinical use. f Psychol 1945;19:87-95.

12 Kendrick D. Cognitive tests for the elderly. Windsor: NFERNelson, 1985.

13 Warrington EK. The recognition memory test. Windsor: NFER-Nelson, 1984

14 Kopelman MD. Remote and autobiographical memory, temporal context memory, and frontal atrophy in Korsakoff and Alzheimer patients. Neuropsychologia 1989;27:437-60.

15 Butters N, Salmon DP, Munro Cullum C, Cairns P, Tröster AI, Jacobs, D. Differentiation of amnesic and demented patients with the Wechsler memory scalerevised. The Clinical Neuropsychologist 1988;2:133-48.

16 Kopelman MD, Wilson BA, Baddeley AD. The autobiographical memory interview. Bury St Edmunds: Thames Valley Test Company, 1990.

17 Kopelman MD. Amnesia: organic and psychogenic. $\mathrm{Br} \mathcal{F}$ Psychiatry 1987;150:428-42.

18 Kopelman MD, Christensen H, Puffett A, Stanhope N. The great escape: a neuropsychological study of psychoThe great escape: a neuropsychological study of p

19 Palmini AL, Gloor P, Jones-Gotman M. Pure amnestic seizures in temporal lobe epilepsy. Brain 1992;115: seizures

20 Milner B. Amnesia following operation on the temporal lobes. In: Whitty CWM, Zangwill eds. Amnesia, lst ed. London: Butterworths, 1966.

21 Zola-Morgan S, Squire LR, Amaral DG. Human amnesia and the medial temporal region: enduring memory impairment following a bilateral lesion limited to field CA1 of the hippocampus. 7 Neurosci 1986;6:2950-67.

22 Kopelman MD. The 'new' and the 'old': components of the anterograde and retrograde memory loss in Korsakoff and Alzheimer patients. In: Squire LR, Butters $\mathrm{N}$, eds. The neuropsychology of memory; 2 nd ed. New York: Guilford, 1992:130-46.

\section{NEUROLOGY IN LITERATURE}

\section{Conversion hysteria/malingering}

The authors of these extracts have, by their descriptions, largely dwelt on malingering rather than conversion hysteria. Katy Carr's paraplegia can only be regarded as hysterical, resolving dramatically after more than two years' incapacity, though it is clearly not her creator's intention for the illness to be regarded in that light. Felix Krull sets out to deceive his medical board by studying the phenomenology of epilepsy. Although allowing credit for his bravura display, one has to wonder at the gullibility of his examining doctors. Catherine Earnshaw is more readily discovered with predictable consequences. Smerdyakov in The Brothers Karamazov exemplifies a problem known to all neurologists-the coincidence of epilepsy and pseudo seizures in the same individual. Kipling's poem deserves to be quoted in full. For all its comic overtones, there is a disturbingly heartless quality to it.

Emily Bronte, 1847, Wuthering Heights

There she lay dashing her head against the arm of the sofa, and grinding her teeth, so that you might fancy she would crush them to splinters! ... In a few seconds she stretched herself out stiff, and turned up her eyes, while her cheeks, at one blanched and livid, assumed the aspect of death .... "There is nothing in the world the matter," I whispered . .

"She has blood on her lips!" he said, shuddering.

"Never mind!" I answered tartly. And I told him how she had resolved, previous to his coming, on exhibiting a fit of frenzy. I incautiously gave the account loud, and she heard me; for she started upher hair flying over her shoulders, her eyes flashing, the muscles of her neck and arms standing out preternaturally. I made up my mind for broken bones at least; but she only glared about her for an instant, and then rushed from the room.

Susan Coolidge, 1872, What Katy did

"Why, I can't stand up!" she gasped, looking very much frightened ....

Dr Alsop sat down beside the sofa and counted Katy's pulse. Then he began feeling all over her.

"Can you move this leg?" he asked. Katy gave a feeble kick.

"And this!?"

The kick was a good deal more feeble ....

"I'm afraid she's done some mischief," he said, at last, but it is impossible to tell yet exactly what ...

"No- the spine is a bone. It is made up of a row of 